\title{
Dentoskeletal Changes in Class II Subjects following Treatment with Twin Block and Herbst Appliance
}

\author{
Dr Khurram Shahzad, ${ }^{1}$ Dr Javeeria Asif Cheema, ${ }^{2}$ Dr Muhammad Azeem, ${ }^{3}$ Dr Waheed Ul Hamid4 \\ 'Resident Orthodontics, Children's Hospital \& Institute of Child Health, Lahore \\ 2Assoc Prof, 4Professor Orthodontics, de'Montmorency College of Dentistry, Lahore, Pakistan \\ ${ }_{3}^{3}$ Asst Prof Orthodontics, Dental Section-Faisalabad Medical University/Punjab Medical College, Pakistan
}

\section{ABSTRACT}

Objective: To compare the mean changes in dentoskeletal parameters in Class II patients treated by Twin Block versus Herbst appliance.

Materials \& Method: The study was conducted at the Orthodontic Department of Children's Hospital and Institute of Child Health and de'Montmorency College of Dentistry, Lahore. The study involved 50 patients those were randomized in equal numbers according to lottery method to either Group-1 (Twin block) or Group-2 (Herbst). Mean changes in SNA, SNB and IMPA at the end of treatment was calculated by subtracting Pretreatment measurements (T1) from post treatment measurements (T2). Student t-test was used to compare the mean changes in dentoskeletal parameters in both groups.

Result: The comparison showed that the mean difference recorded in SNA values was $-1.06 \pm 0.62$ in Group-1 and $-1.28 \pm 0.61$ in Group-2 ( $p$-Value 0.07), SNB was $2.14 \pm 0.70$ in Group-1 and 1.22 \pm 0.55 in Group-2, (p-Value 0.001) while IMPA was $1.58 \pm 0.64$ in Group-1 and 4.8 \pm 1.31 in Group-2 (p-Value 0.001).

Conclusion: There was a significant difference between mean changes in dentoskeletal parameters in Class II patients treated by twin block when compared to Herbst appliance.

Keywords: Class II malocclusion, dentoskeletal, Twin Block, Herbst

\section{INTRODUCTION}

Treatment plan of growing Class II patients should be directed towards solving the dento-skeletal disharmony in order to obtain favorable facial aesthetics. ${ }^{1,2}$ Treatment of Class II malocclusion may involve the use of orthopedic appliances, extra oral traction and functional appliances. Functional appliance therapy is a commonly used treatment protocol for growing Class II patients with mandibular deficiency. ${ }^{3}$

The selection of functional appliances is dependent upon several factors which can be categorized into patient factors e.g. age and compliance, and clinical factors e.g. preference/familiarity and laboratory facilities. Different types of functional appliances are available for the correction of Class II skeletal and occlusal disharmonies. ${ }^{4}$ Twin Block (TB) and Herbst (HB) appliances are among the most popular functional appliances. ${ }^{5}$ TB appliance is the most preferred functional appliance in UK, ${ }^{6}$ and $\mathrm{HB}$ is most commonly used in USA?
TB was first introduced by Clark in 1988 and consists of two separate, upper and lower, removable plates with acrylic blocks trimmed to an angle of 70 degrees. ${ }^{8} \mathrm{~TB}$ is widely used because of its high patient acceptability and ability to produce rapid treatment changes. 8 The HB appliance was first introduced in 1900s by Emil Herbst as a fixed bite-jumping device, and later Pancherz reintroduced it in the 1970's as a banded appliance. ${ }^{9}$ It has been reported that HB appliance can correct Class II skeletal problems by encouraging mandibular growth. ${ }^{10}$

Many studies have been carried out on soft tissue effects of these appliances, ${ }^{2-5}$ but only a few studies have compared the dentoskeletal effects of TB and HB in Class II patients. 11-13 In addition, no single study has been carried out specifically on dentoskeletal effects of TB and HB in South Asian population. It should be kept in mind that skeletal effects vary among subjects, between gender groups, with genetic influence and with the time of therapy. 
Thus the objective of this study was to compare the mean changes in dentoskeletal parameters in Class ॥ patients treated by Twin Block versus Herbst appliance. Our hypothesis was that there is a difference between mean changes of dentoskeletal parameters (SNA, SNB \& (MPA) in Class II patients treated by twin block versus Herbst appliance.

\section{MATERIALS AND METHOD}

The randomized controlled trial was conducted after taking ethical approval and informed consent in the Orthodontic Department of Children's Hospital and Institute of Child Health and de'Montmorency College of Dentistry, Lahore, Pakistan. Sample size of 50 cases ( 25 in each group) was calculated with $95 \%$ confidence level, $80 \%$ power of test, and taking expected mean \pm S.D of mean change in SNA in both groups, i.e. $-1.35 \pm 1.11$ in Herbst group vs. $-0.75 \pm 1.03$ in Twin block group in Class 11 patients. ${ }^{13}$

Patients were selected according to following inclusion criteria: Skeletal Class II relationship (ANB $>4^{\circ}$, $S N B<78^{\circ}$ ), patients' age ranged between 9-13 years, Overjet $\geq 5 \mathrm{~mm}, \mathrm{SN}-\mathrm{MP}=32^{\circ} \pm 4^{\circ}$ and bilateral Class II molar and canine relation. Patients with previous history of orthodontic treatment, congenitally missing or extracted permanent tooth (except third molars) and syndromes, skeletal dysplasia were excluded.

Study involved 50 patients those were randomized in equal numbers according to lottery method to either Group-1 (Twin block) or Group-2 (Herbst). For Group-l, Twin block group patients were instructed to wear the appliance full time. For Group II, Acrylic splint design of Herbst was inserted. When a normal or corrected overjet in retruded position was recorded, the active treatment was finished and cephalometric records of patients were taken in both groups.

Dentoskeletal measurements (SNA, SNB \& IMPA) were measured on lateral cephalometric radiographs before start of the treatment and at the time of removal of appliance and these measurements were taken by the researcher himself to address bias. Mean of dentoskeletal changes was measured at the end of treatment by calculating the difference between posttreatment and pre-treatment values taken on lateral cephalogram. In dental part; only one value of Lower incisor to mandibular plane angle (IMPA) was taken by measuring the angle between body of mandible and long axis of most proclined lower mandibular incisor. In skeletal part; two measurements were taken: SNA angle (SNA): inward angle between NA line and Sellanasion (SN) plane with normal value $80-84^{\circ}$, SNB angle (SNB): inward angle between NB line and SN plane with normal value $78-82^{\circ}$.

All statistical analysis was done using SPSS 20.0. Pre-treatment and Post treatment dentoskeletal measurements and age were presented as means and standard deviation. Gender was presented by frequency and percentage. Mean changes in SNA, SNB and IMPA at the end of treatment was calculated by subtracting Pretreatment measurements ( $\mathrm{T} 1$ ) from post treatment measurements (T2). Student $t$-test was used to compare the mean changes in dentoskeletal parameters in both groups. $\mathrm{p} \leq 0.05$ was considered as significant. The data was stratified for age and gender, to address the effect modifiers. Post stratification student t-test was applied to check the significance, with $p \leq 0.05$ as significant.

\section{RESULT}

Age and gender distribution of the patients is shown in Table 1. Comparison of mean changes in dentoskeletal parameters in Class II patients treated by Twin block versus Herbst appliance is given in Table 2. The data were stratified for age and gender to control the effect modifiers, which showed insignificant findings with regards to age and gender.

Table 1: Distribution of sample according to age and gender

\begin{tabular}{|c|c|c|c|c|c|}
\hline \multirow{2}{*}{\multicolumn{2}{|c|}{ Sample }} & \multicolumn{2}{|c|}{ Group- 1 (Twin block) n=25 } & \multicolumn{2}{|c|}{ Group-2 (Herbst) $n=25$} \\
\hline & & No. & $\%$ & No. & $\%$ \\
\hline \multirow{3}{*}{$\begin{array}{l}\text { Age } \\
\text { (in years) }\end{array}$} & $9-11$ & 18 & 72 & 16 & 64 \\
\hline & $12-13$ & 7 & 28 & 9 & 36 \\
\hline & Mean & \multicolumn{2}{|c|}{$10.66 \pm 1.32$} & \multicolumn{2}{|c|}{$10.86 \pm 1.41$} \\
\hline \multirow{2}{*}{ Gender } & Male & 10 & 40 & 9 & 36 \\
\hline & Female & 15 & 60 & 16 & 64 \\
\hline \multicolumn{2}{|c|}{ Total } & 25 & 100 & 25 & 100 \\
\hline
\end{tabular}


Table 2: Comparison of mean change in dentoskeletal parameters

\begin{tabular}{|c|c|c|c|c|c|c|}
\hline \multirow{2}{*}{\multicolumn{2}{|c|}{ Parameter }} & \multicolumn{2}{|c|}{ Group-1 (Twin block) } & \multicolumn{2}{|c|}{ Group-2 (Herbst) } & \multirow{3}{*}{$\begin{array}{c}\text { p-Value } \\
0.37\end{array}$} \\
\hline & & \multirow{2}{*}{$\begin{array}{c}\text { Mean } \\
82.24\end{array}$} & \multirow{2}{*}{$\begin{array}{c}\text { SD } \\
0.82\end{array}$} & \multirow{2}{*}{$\begin{array}{c}\text { Mean } \\
82.08\end{array}$} & \multirow{2}{*}{$\begin{array}{c}\text { SD } \\
0.97\end{array}$} & \\
\hline \multirow{3}{*}{ Pre-treatment } & SNA & & & & & \\
\hline & SNB & 75.26 & 1.29 & 75.12 & 1.32 & 0.59 \\
\hline & IMPA & 95.62 & 2.27 & 95.82 & 2.32 & 0.66 \\
\hline \multirow{3}{*}{ Post-treatment } & SNA & 81.18 & 0.77 & 80.80 & 1.16 & $0.05^{*}$ \\
\hline & SNB & 84.38 & 1.07 & 76.34 & 1.44 & $0.001^{*}$ \\
\hline & IMPA & 97.20 & 2.33 & 100.62 & 2.83 & $0.001^{*}$ \\
\hline \multirow{3}{*}{ Mean difference } & SNA & -1.06 & 0.62 & -1.28 & 0.61 & 0.07 \\
\hline & SNB & 2.14 & 0.70 & 1.22 & 0.55 & $0.001^{*}$ \\
\hline & IMPA & 1.58 & 0.64 & 4.80 & 1.31 & $0.001^{*}$ \\
\hline
\end{tabular}

*Statistically significant at $p \leq 0.05$

The differences in mean pre-treatment SNA values were not statistically significant. Mean post-treatment SNA values were 81.18 in Group-1 and 80.8 in Group-2, SNB was 84.38 in Group-1 and 76.34 in Group-2, IMPA was 97.2 in Group-1 and 100.62 in Group-2. The differences were significant. The findings for post-treatment mean difference in SNA values was -1.06 in Group-1 and -1.28 in Group-2, SNB was 2.14 in Group-1 and 1.22 in Group-2, IMPA was 1.58 in Group-1 and 4.8 in Group-2. The differences were significant, except for SNA values.

\section{DISCUSSION}

Results of the current study showed that there was a significant difference between mean changes in dentoskeletal parameters (SNA, SNB, IMPA) in Class II patients treated by twin block when compared to Herbst appliance. In comparison of results of Baysal and Uysal, ${ }^{13}$ SNB angle was increased in Twin block group than in Herbst group. The change in SNA angle was greater for Herbst group than that in Twin block group. The increase in lower incisor proclination (IMPA) was also found greater in Herbst group than that in Twin Block group. Similar findings were recorded in our study.

Schaefer et $\mathrm{al}^{14}$ compared the effects of Twin-block vs. Herbst for correcting Class II disharmony, they were of the view that treatment effects of both protocols led to a normalization of dentoskeletal parameters at the end of the overall treatment period. However, only minor differences were detected in the treatment and post-treatment effects of crown herbst and twin-block appliance.

It is well known that a point in disfavor of HB treatment is a proclination of lower incisors due to the forces exerted on the lower teeth by the same telescope device. Various modifications of original HB have been proposed to counter the proclination of mandibular incisors. ${ }^{15}$ It has been proved in the literature that functional appliances do not produce long term skeletal changes and most of their effects are dentoalveloar. ${ }^{16}$ In a prospective controlled trial with twin blocks and controls to investigate the skeletal and dental effects showed that the ANB angle reduced by $2^{\circ}$ which was almost entirely due to mandibular length increase which was $2.4 \mathrm{~mm}$ compared to the controls and there was no evidence of a restriction in maxillary growth. ${ }^{17}$

Limitations of this study are sample size and single centre approach. Further studies are required to validate results of current study.

\section{CONCLUSION}

There was a significant difference between mean changes in dentoskeletal parameters in Class II patients treated by twin block when compared to Herbst appliance. 


\section{REFERENCES}

1. Dann C, Phillips C, Broder HL, Tulloch JF. Self-concept, Class II malocclusion and early treatment. Angle Orthod. 1995;65:41 1-6.

2. Quintão C, Brunharo HVP, Menezes RC, Almeida MAO. Soft tissue facial profile changes following functional appliance therapy. Eur J Orthod. 2006;28:35-41.

3. Baysal A, Uysal T. Soft tissue effects of Twin Block and Herbst appliances in patients with Class II division 1 mandibular retrognathy. Eur J Orthod. 2013;35:71-81.

4. Alves PFR, Oliverira AG. World J Orthod. 2008;9:62,e.1-19.

5. Schaefer AT, McNamara JA Jr, Franchi L, Baccetti T. A cephalometric comparison of treatment with the Twin-block and stainless steel crown Herbst appliances followed by fixed appliance therapy. Am J Orthod Dentofac Orthop. 2004;126:7-15.

6. O'Brien K. Is early treatment for Class II malocclusion effective? Results from a randomized controlled trial. Am J Orthod Dentof Orthop. 2006;129:64-5.

7. MCNamara JA Jr, Brudon WL. Orthodontics \& Dentofacial Orthopedics. 2001; Needham, Michigan.

8. Clark WJ. Twin Block functional therapy: Applications in Dentofacial Orthopedics, 2002; 2nd edn. Mosby, London.

9. Pancherz H. The Herbst appliance: Its biological effects and clinical use. Am J Orthod. 1985;87:1-20.

10. Burkhardt DR, MCNamara JA Jr, Bacetti T. Maxillary molar distalization or mandibular advancement: A cephalometric comparison of comprehensive orthodontic treatment including the pendulum and Herbst appliances. Am J Orthod Dentofac Orthop 2003;123:108-16.

11. Illing HM, Morris DO, Lee RT. A prospective evaluation of Bass, Bionator and Twinblock appliances. Part I: The hard tissues. Eur J Orthodontics 1998;20:501-16.

12. Siara-Olds NJ, Kulbershb VP, Bergerc J, Bayirli B. Long-term dentoskeletal changes with the Bionator, Herbst, Twin Block, and MARA functional appliances. Angle Orthod. 2010;80:18-29.

13. Asli Baysal, Tancan Uysal. Dentoskeletal effects of Twin Block and Herbst appliances in patients with Class II division 1 mandibular retrognathy. Euro J Orthod. 2014;36:164-72.

14. Schaefer AT, MCNamara JA Jr, Franchi L, Baccetti T. A cephalometric comparison of treatment with the Twin-block and stainless steel crown Herbst appliances followed by fixed appliance therapy. Am J Orthod Dentofac Orthop. 2004;126(1):7-15.

15. Gracco A, Luca L, Siciliani G. Molar distalization with skeletal anchorage. Aust Orthod J. 2007;23:147-52.

16. Lee RT, Kyi CS, Mack GJ. A controlled clinical trial of the effects of the Twin Block and Dynamax appliances on the hard and soft tissues. Eur J Ortho. 2007;29(3):272-82.

17. Lund DI, Sandler PJ. The effect of Twin Blocks: A prospective controlled study. Am J Orthod Dentofac Orthop 1998;1 13:104-10. 